\title{
1. Introduction: family policy in comparative perspective
}

In a not too distant future, if not already at present, most mature welfare democracies will be faced with one of the greatest challenges in the history of the welfare state. Populations are rapidly ageing at the same time as fertility levels have decreased. An increasing number of women in these countries opt for a labour market career before childbearing, in large part reflecting an underlying conflict between work and family. At the same time a general trend towards increasing income inequalities and poverty prevails in many countries, where child poverty recently has been paid closer attention due to the potential adverse consequences for well-being of children as well as for their future labour market prospects. Changing the balance in the family-state-market relationship by increasing gender equality and by increasing the possibilities of women and men to reconcile labour market participation and children through family policy are often pointed out as key ways of influencing such developments, but still little systematic knowledge exists about the long-run causes and consequences of different family policy strategies.

The purpose of this book is to analyse structures, determinants and outcomes of family policy legislation in 18 post-war welfare democracies from a macro-sociological and institutional perspective. A main question is to what extent the motives of different family policy institutions can be linked to childbearing, women's work, child poverty and gender role attitudes. The rationale behind applying this macro-comparative and institutional perspective is to draw the broad contours of family policy legislation, and of its causes and consequences in Western societies rather than to paint a detailed picture of each country's socio-political, demographic and socioeconomic landscape.

Welfare state regimes are often assumed to be important for the shaping of individual well-being. Social policy arrangements are, for example, likely to affect the living conditions, actions, orientations and, in a wider sense, the agency or capabilities of citizens. When legislating social security transfers or services, policymakers modify the bundle of choices available to an

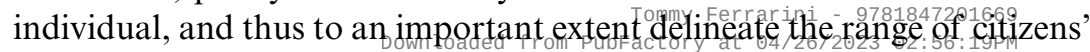


personal agency. Social policy thereby affects agency by changing the 'capabilities' of individuals to choose between different 'achievements', to use the terminology of Sen (1992). As argued by Korpi and Palme (1998) the institutions of the welfare state can here be viewed as 'intervening variables'. The structure of incentives embedded in institutions to a large degree reflects the underlying motives of policymakers and other social actors, actively pursuing particular goals or responding to structural-economic pressures, and these structures of incentives in turn contribute to pattern citizens' choices and actions. Institutions of the welfare state can also be seen as normative orders with the potential to structure preferences, attitudes and world orientations of individuals (see March and Olsen 1989; Sjöberg 2004; Esser 2005). Cross-national differences in social policy legislation may thus be expected to link up with divergent underlying factors driving institutional development as well as with diverse outcomes of different institutions, even if it should be emphasized that social policy institutions can always have both intended and unintended consequences.

The relevance of the welfare state for the relationship between family, state and the labour market has received recognition in comparative welfare state research (see Esping-Andersen 1990). A growing literature has also highlighted the need for a more extensive gender perspective on the statemarket-family relationship (for example Hobson 1990; Lewis 1992; Orloff 1993; Sainsbury 1996; O’Connor et al. 1999; Palme 1999a). In consequence, the 'searchlight' of welfare state researchers has increasingly been directed towards relatively under-explained domains of welfare states, such as different aspects of family policy transfers and services. The interest in family policy institutions reflects their potential to structure gender inequalities and agency of parents in many ways, a main way being the regulation of female labour force participation and the organization of care work, by structuring poverty risks as well as childbearing decisions, thus affecting the well-being of individual men and women.

For example, the provision of adequate resources to mothers by supporting female employment through public transfers and services has been thought to affect the agency of all mothers. By allowing women to divorce without greater risk of becoming poor, welfare state institutions improve women's bargaining positions within the family and thereby also increase their choice capacities (Hobson 1990; Orloff 1993). Institutions of family policy may also change the agency of fathers in terms of capabilities to participate in care work, or 'fathering' (Bergman and Hobson 2002). However, family policy legislation has frequently worked to sustain more traditional divisions of work by supporting mothers in the role of homemakers (Lewis 1992; Wennemo 1994; Montanari 2000). Cross-national differences in design of such social policy transfers and services havempurturherini 
to the motives and relative strengths of different political actors (Korpi 2000; Ferrarini 2003). This underscores the importance to separate different dimensions of family policy in the analysis of causes and consequences of such policies.

A comparative approach to the study of living conditions, agency and world orientations of individuals can greatly benefit from a focus on institutions. This holds for the sociological classics as well as for most presentday researchers. Even when Weber (1921) applied perspectives emphasizing the purposeful actions of individuals, this approach is more institutionalist than voluntarist. Social institutions affect agency of individuals profoundly, and the main way for agency to change social structures is precisely via such institutions. As Goodin (1996) points out, rational action explanations could greatly benefit from an institutional perspective, in that institutions can be viewed as a link between social structure and agency.

The family policy transfers that are included in the analyses in this book are parental leave benefits directed to mothers, fathers or both parents to facilitate childcare during the early post-natal period, child benefits paid in cash or via the tax system as well as so-called marriage subsidies that are distributed to wage earners with an economically dependent spouse. By disaggregating different aspects of such institutions, we can improve the possibilities to analyse how family policy legislation shapes agency, actions and living conditions of individuals, parents as well as children. For the purpose of these analyses, I have collected new longitudinal data on parental leave institutions that are combined in the analyses with existing data on child benefits and marriage subsidies paid in cash or via the tax system. The book is mainly confined to the period 1950 to 2000, with a particular focus on the latter half of this period, and the following countries are included: Australia, Austria, Belgium, Canada, Denmark, Finland, France, Germany, Ireland, Italy, Japan, the Netherlands, New Zealand, Norway, Sweden, Switzerland, the United Kingdom and the United States.

A number of sub-questions are addressed in the book. First, I analyse the development of different family policy strategies during the post-war period and in particular how different welfare states have oriented such institutions towards providing parents with incentives to participate in paid and unpaid work. Family policy transfers are also evaluated against aspects of the broader family policy matrix, including public services such as child and elder care, by the end of the twentieth century. Second, the roles of potential causal factors behind different institutional developments are analysed. Third, I evaluate the links between institutional design of family policy and patterns of parental actions, in the form of female labour force participation and fertility. Fourth, the relationship between family policy

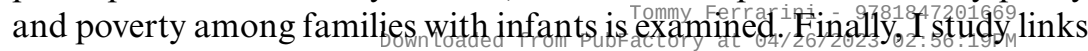


between models of family policy and attitudes to women's work as well as perceived problems in reconciling paid and unpaid work. All these questions are explicitly analysed from a comparative perspective.

Several theoretical, methodological and empirical topics of relevance for upcoming analyses are dealt with in this introductory chapter. To start with, the role of different family policy institutions is discussed. Since institutional development is an important theme in the book, theories of institutional change are discussed in the subsequent section. The two following sections examine methodological advantages and problems with the comparative approach as here defined as well as analytical devices to facilitate crossnational comparison by the use of typologies. Thereafter, the models and dimensions of family policy that are to be used throughout the empirical chapters of the study are critically examined. Following this, the enactment of family policy transfers is situated in the broader institutional context of other social insurance programmes. The penultimate section includes a discussion of data and measurement issues of central importance for the empirical studies. Finally, a brief outline of the sub-studies in the upcoming chapters is offered.

\section{FAMILY POLICY INSTITUTIONS IN WESTERN WELFARE DEMOCRACIES}

Without information on the legislative structures of social policies, any attempt to explain why welfare states diverge in structure and outcome is rendered difficult. Early comparative studies of welfare state development mainly analysed aggregate expenditure levels in different social policy areas (see Cutright 1965; Wilensky 1975; Pampel and Williamson 1985). Even if spending levels recently have been disaggregated by programme area (Castles 1998; Huber and Stephens 2000), they still suffer from an institutional deficit since demographic factors and labour market conditions are still likely to influence welfare state expenditure besides social policy legislation in itself. Furthermore, even if we are able to account for such factors, expenditure in itself adds little information on the content and the incentive structures of particular types of legislation. The focus on legislated social rights may therefore be described as a crucial link in the study of causes and consequences of welfare states (Korpi 1989; Esping-Andersen 1990; Palme 1990; Kangas 1991; Carroll 1999).

Extending the analysis to the field of social rights in family policy is motivated for several reasons. First, there is in this area a lack of broad comparative studies oriented towards the integrated and systematic study of both causes and consequences of socialy policrining titutitions. 
family policy benefits are likely to structure a number of outcomes relevant for gender relations and agency of parents more directly than do other social insurance programmes such as for example sickness insurance and unemployment benefits, also raising questions about different underlying socio-political causes of different institutions' development.

Some aspects of family policy legislation have previously been studied in a systematic comparative, institutional and longitudinal perspective, for example regarding marriage subsidies (Montanari 2000) and child benefits (Wennemo 1994). Paid parental leave has also been the subject of analysis in several comparative studies with a systematic and institutional focus (Kamerman and Kahn 1991; Sainsbury 1996, 1999; Moss and Deven 1999; Bruning and Plantega 1999; Deven and Moss 2002), and some studies have also extended the analysis of paid parental leave to longer time periods (for example Ruhm 1998). There is, however, a lack of studies that systematically separate different institutional features of paid parental leave and apply a comparative longitudinal perspective simultaneously. If we want to analyse how family policy contributes to shaping the agency of parents, it is, for example, of vital interest to separate earnings-related benefits from flat-rate benefits. Moreover, to analyse institutional change, longitudinal data is necessary. Not only may earnings-related benefits provide larger economic resources to given households, but they are generally also likely to be important in shaping women's incentives to enter the labour market and in encouraging men to participate in unpaid care work when the father is entitled to such benefits. The lack of analyses on parental leave institutions motivates that particular attention is paid to such benefits in the upcoming chapter.

Family policy transfer programmes do naturally not exist in isolation from other parts of social policy systems, but are integrated within a larger social policy context. The relatively generous legislated parental leave benefits in the Nordic countries, for example, coexist with well-developed public childcare services for the youngest, while countries with relatively meagre parental leave provisions also tend to have less developed public services for the youngest individuals. Such overall orientations of social policy have led researchers to label countries as having different gender regimes or family policy models (see Lewis 1992; Sainsbury 1996; Korpi 2000).

The main reason why the development of public services, such as childcare and elder care, have not been studied in a broadly comparative and longitudinal way has to do with a lack of reliable longitudinal information, which may reflect both the complex institutional nature of service provision and a tendency to provide such public services on the local rather than the state level, making comparable statistical information less accessible. This

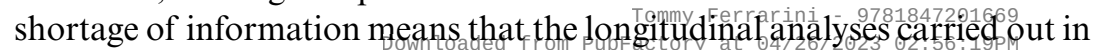


this book have to be mainly confined to the study of family policy transfers. However, analyses of policy interactions between family policy transfers and public services are to be performed for the end of the observation period for which comparable data on such services exist. These analyses may be important for the understanding of how broader family policy models function, and may provide a provisional answer to the question of to what extent family policy transfers may serve as valid indicators for analyses of broader family policy developments. However, this does not mean that an analytical approach to the study of particular family policy transfers is not warranted in itself. Before proceeding to an analysis of policy interactions, more in-depth institutional knowledge about different parts of family policy systems is needed. We have to be more specific about given programme types before generalizing extensively about the wider family policy area.

\section{INSTITUTIONS AND INSTITUTIONAL CHANGE}

When attempting to explain potential outcomes of welfare state institutions it is of great interest to know more about their potential underlying causes, since social policy institutions themselves can be seen as a partial reflection of their underlying motives. Goodin (1996) outlines three ways in which social institutions may develop and change over time. First, institutions could evolve by accident without any particular driving force. Second, they may develop through evolution; the types of institutions surviving at the end of a given time period are in some ways supposed to be 'better fitted' to their particular social and economic environment. Third, institutional change may be a product of intentional intervention by purposive agents, individuals as well as organized groups. Goodin (1996: 25) points out that 'any actual instance of social or institutional change is almost certain to involve a combination of all three of these elements'.

Theories on the development of the welfare state, however, rarely state that social policy institutions have come into place by accident, even if they may have unintended consequences. Instead the main explanations are underpinned by evolutionary or rational action ideas. The 'logic of industrialism' perspective sees the institutions of the welfare state as a necessary evolutionary outcome of economic processes of industrialization (Kerr et al. 1960; Wilensky 1975, 1976). More recent perspectives on welfare state retrenchment also emphasize the importance of structural economic processes as causes of welfare state change (Castles 2001; Huber and Stephens 2001).

While recognizing the relevance of structural and economic factors, the

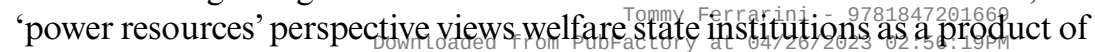


distributive conflict between purposeful and goal-oriented social and political actors with different distributions of economic and political power resources (Korpi 1985, 1989; Esping-Andersen 1990). A perspective focused on power relations is not only applicable to analyse class-political conflicts, but has sometimes been applied to analyse female agency and gender dimensions of welfare states, in particular regarding the relationship between organized women's interests and family policy legislation (see Hobson and Lindholm 1997; Huber and Stephens 2000). Such women's interests are, however, also likely to be mediated by other organizations, for example through existing political parties (Sainsbury 1999).

A perspective emphasizing the importance of institutional structures of welfare states may also dynamically complement rational action theories of institutional development. The basic idea is here that the success of implementing new social policy institutions is affected also by prior legacies in welfare state legislation. To different degrees, social policy institutions may embody built-in interests, something which makes certain types of institutions more resistant to change than others (Korpi 2001). Furthermore, the wider institutional setting could structure social policy change. For example, state constitutional structure, by availing constitutional 'veto points' that political opponents of a particular reform can access, is one factor that may raise constraints for the implementation of welfare state institutions (Huber et al. 1993, 1997).

\section{A COMPARATIVE APPROACH}

In testing hypotheses derived from theories on welfare state development and outcomes, it is fruitful to use cross-national comparisons, not least since social policy institutions in a particular national context often only undergo limited change, at least over the short to medium term. Most varieties of social scientific inquiry can be said to involve comparisons of some sort, also analyses of individuals in large micro-level data sets. However, the term 'comparative' is typically reserved for studies that include comparisons of macro-units, most often in the form of countries (Ragin 1987). Crossnational comparison often entails use of some kind of a 'quasi-experimental' method when links between institutions and outcomes or between potential causes and institutions are to be explained. A macro-comparative approach to the study of family policy programmes allows for an analysis of different institutional strategies in the provision of economic support to families with children. Combined with a longitudinal perspective, such an approach also enhances the possibilities to study causes and outcomes of programmes of family policy.

Tommy Ferrarini - 9781847201669 
Comparative research has a longstanding sociological tradition. Several of sociology's 'founding fathers' employ cross-national and historical comparative analyses to account for social change. Marx (1857) used comparisons of different societies to define different stages in the development of the relations of production and class struggle. Weber (1922) compared the economic ethics of the dominant strata of the five world religions to reach a better understanding of how and why the rational economic ethic of capitalism developed, and he also conducted comparative institutional analyses within law, bureaucracy and politics (Weber 1921). Durkheim defined sociology itself as an intrinsically comparative science. He developed a particular 'comparative method' for the explanation of social phenomena, since traditional experimental scientific method could not be applicable to whole societies. In fact, it is stated in Durkheim's Rules of Sociological Method (1895: 157) that this comparative method constitutes sociology in itself if it aspires to account for, and explain, social facts.

Few would agree today with the statement that cross-country comparisons are the only means by which we can explain sociological phenomena and social change. However, it cannot be denied that a comparative approach can give important insights into processes of institutional development and how institutions affect living conditions, actions, attitudes and agency of individuals. The capability to identify and explain institutional diversity and change within different social settings, as well as over time, is perhaps the main strength of a comparative sociological approach, something that holds true as much for the sociological classics as for sociologists studying 'post-industrial' societies (see Esping-Andersen 2000).

There are several reasons why in particular macro-comparative research is potentially valuable when analysing welfare state change and institutional outcomes. Any attempt to explain a national outcome with reference to other societies basically involves comparative inquiry. Ragin (1987:9) takes an example from a hypothetical investigation that would aim to explain strong class voting in Britain with the fact that it is an industrial society. To state that a particular national outcome is due to a country being 'industrial' presupposes that we can identify other countries that belong to this particular category, and that we can compare them on relevant dimensions with countries that are not industrial.

Even with access to rich quantitative cross-sectional data for a single country, it may be difficult to establish effects of welfare state institutions on behaviour or living conditions of individuals. If we, for example, want to analyse the impact of parental leave or marriage subsidies on female labour force participation, a large random sample of individuals in single countries at a specific point of time may do little to enhance our understanding of the

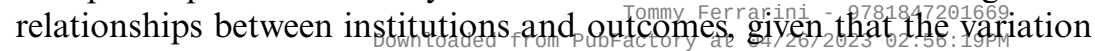


of particular welfare state's institutions at the time is small or non-existent. A longitudinal approach may be of help, but sometimes welfare state institutions in a given country undergo relatively little change also over rather long time periods. Indeed, it has been pointed out that temporal variation in state-legislated social policy in single-country research often is non-existent (Bäckman 1998; Sjöberg 2000). By conducting analyses spanning over several national institutional settings as well as different time periods we improve our position to test hypotheses about welfare state causes and outcomes.

\section{TYPOLOGIES OF WELFARE STATES}

When comparing countries it is difficult to hold all possible explanatory factors under control, due to the relatively limited number of possible observation units. Approaches by which this problem can be reduced is through a selection of 'most comparable cases' (Lijphart 1975), as well as by the use of typologies (Leibfried 1992; Abrahamsson 1999; Arts and Gelissen 2002). The strategy of most comparable cases implies the selection of countries with variation with respect to independent variables, the effects of which we want to study, but which are relatively similar with respect to 'confounding' variables, thereby strategically reducing the number of potential sources of variation between the cases that are to be compared. The cases included in this study are, for example, all advanced industrial countries with an uninterrupted democratic tradition since the Second World War and a population exceeding one million.

A further method by which the number of different confounding factors can be reduced, and countries can be systematically grouped, is by means of a typology (for a general introduction to typology construction, see Bailey 1994). Typologies in the comparative branch of the social sciences are often constructed on the basis of some kind of more or less explicit 'most comparable cases' assumption, for example by restricting the scope of the typology to highly industrialized democracies. Welfare state typologies order countries into different classes on the basis of more or less explicit criteria, such as the institutional design of political and social policy institutions, labour market outcomes or structures of inequality in the welfare state. The typology thus at the same time ascribes similarities to countries within the same ideal-typical category, as well as positing dissimilarities between groups of countries in different categories. Thereby several sources of variation between cases are reduced. With the increasing interest in cross-national

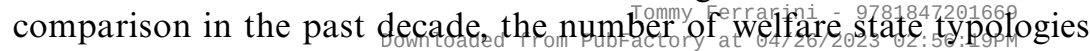


has flourished (for a review see for example Abrahamsson 1999; Arts and Gelissen 2002).

Perhaps one of the most influential welfare state typologies is EspingAndersen's (1990) categorization of three distinct welfare regimes, a typology which modifies and modernizes the original tripartite division introduced by Titmuss (1974). Esping-Andersen uses a set of multidimensional indicators spanning causal factors, welfare state institutions and policy outcomes when arriving at a liberal, a social-democratic and a conservative regime type. This typology has been widely used in comparative welfare state research, but has also been subject to criticism from different theoretical perspectives and has stimulated a large number of innovations in terms of welfare state typologies (Arts and Gelissen 2002).

Castles and Mitchell (1991), for example, criticized Esping-Andersen early on for his handling of means-tested welfare state programmes. When modifying the original indicators to reflect if means-testing was used only to include the poor or to include all but the richest, they found a split in the liberal regime type and thereby arrived at four categories instead of three, including a new 'radical' world of welfare states. This exercise highlights the sensitivity of the typology to the selection of underlying criteria and choices of operationalization. Leibfried (1992) also added a fourth model to Titmuss/Esping-Andersen's tripartite typology, but here the new cluster consists of a 'rudimentary' type of welfare state found in Southern Europe, a part of the world relatively overlooked by previous typology-makers. The scope of the most comparable cases assumption guiding the choice of included countries hereby also may strongly influence the end result.

Korpi and Palme (1998) question the validity of earlier regime-type approaches from a different angle. They argue that by being based on indicators simultaneously reflecting causes, intervening variables as well as outcomes, Esping-Andersen's typology may be useful for descriptive purposes but is less fruitful when the researcher has explanatory ambitions. Instead Korpi and Palme propose the use of purely institutional indicators of central domains of social insurance systems when constructing their typology. Institutional variations thus indexed can then, on one hand, be explained in terms of, for example, political factors, and on the other hand, be causally related to particular outcomes, such as income inequalities. The latter approach thereby seems particularly well suited for the purpose of this book.

From a gender perspective, a number of shortcomings of earlier welfare state typologies have been pointed out. By being based on theoretical criteria that primarily are related to social class and largely leaving out the family, several of the typologies discussed above are claimed to have

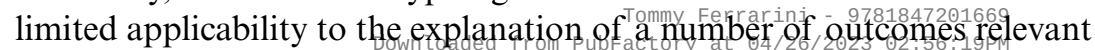


for gender relations (Lewis 1992; Orloff 1993; Sainsbury 1996). Attempts to create gender sensitive typologies, however, sometimes seem to share some of the weaknesses of Esping-Andersen's regime types in that causes and effects, policy and potential outcomes, are partly conflated (see Hobson 1994; Sainsbury 1999). This is manifested particularly in that the underlying classification criteria often both include institutions (as causes, or as mediating variables) and the outcomes of interest for study (such as female labour force participation). Thereby, since the explanandum is constitutive of the typology, serious problems can come up in using the typology as an aid for explanations, which can end up being tautological.

For example, in Lewis's (1992) influential concept of male breadwinner regimes, social policies of all existing welfare states are seen as to different degrees approximating a male breadwinner norm, where support is directed to families with a housewife and a full-time male earner. Yet an essential underlying dimension of variation between welfare states in Lewis's typology is also the extent to which women have been recognized as workers. In a similar fashion, Siaroff (1994) mixes up family policy institutions and labour market inequalities in an attempt to modify Esping-Andersen's (1990) typology into more gender sensitive shape.

Sainsbury (1996) points out that the male breadwinner regime concept is one-dimensional and cannot capture the existing patterns of variation between welfare states. She instead proposes a distinction between a male breadwinner model and an individual model of social policy, based on a number of dimensions of social policy, such as whether the dominant familial ideology supports marriage and a strict within-family division of labour, and to what extent units and recipients of benefits are households or individuals. It is held by Sainsbury that the explanatory potential of a typology is increased by a simultaneously institutional and multidimensional approach (see also Bonoli 1997).

An interesting attempt to develop a family policy typology based on the dimension of care has been developed by Linda Haas (2003). This typology to large extent builds on family policy legislation (in particular parental leave and public child care) in European Union countries. In analogy to Leibfried (1992) she finds that Southern European countries fall into the same regime. Even though this typology has an institutional starting point it also seems to merge institutions with outcomes - by, for example, including female labour force participation as criterion for separating different models.

Another relatively recent contribution to the welfare state typology business is Korpi's (2000) gender-sensitive family policy typology. ${ }^{1}$ A clear advance for this typology compared to several of its predecessors is that it is explicitly two-dimensional and based only on institutional family policy

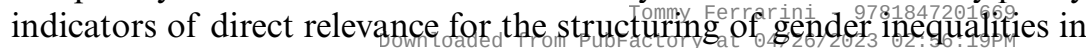


agency. An additional advantage is that Korpi allows countries to score simultaneously on continuous scales on the underlying dimensions. By allowing each country's family policy to vary along different dimensions of policy institutions, diverging causes and consequences of institutional developments can be more easily evaluated within and between countries. Thereby it can more fruitfully be used to explain different socioeconomic and gender relevant outcomes, such as cross-national variation in female labour force participation. The gains of such an approach suggest its usefulness in this study, and therefore a more thorough discussion of the family policy typology and its underlying dimensions is carried out in the upcoming section.

\section{MODELS OF FAMILY POLICY}

In Korpi's family policy typology, as noted characteristics of family policy institutions are arranged along two separate dimensions, depending on whether they support a traditional family (general family support), or whether they support a dual earner family (dual earner support). These types of support are expected to structure the agency of parents in different ways. General family support maintains a family type where the father is the main earner and the mother mainly is expected to see to care work in the family. Dual earner support is more oriented towards extending mothers' capabilities to participate in both labour market careers and in care work at home, and may also provide fathers with incentives to engage in care work. The indicators used include aspects of paid leave, together with the scope of public services to families and other transfers paid in cash or via the tax system. ${ }^{2}$ On the basis of these dimensions three different ideal-typical family policy strategies are discerned. Figure 1.1 illustrates the ordering of family policies along the two underlying analytical dimensions.

Welfare states with well-developed support to the traditional family are grouped within a general family support cluster, corresponding to cell A in the figure. Of our countries, Austria, Belgium, France, Germany, Ireland, Italy and the Netherlands belonged to this model of family policy by the turn of the twentieth century. Countries with generous dual earner support are grouped as adhering to a dual earner model of family policy, illustrated by cell D in the figure, with Denmark, Finland, Norway and Sweden having developed such family policies. A market-based family policy model is followed by welfare states with less developed family policies along both dimensions (cell C). Countries with market-oriented family policies include Australia, Canada, Japan, New Zealand, Switzerland, the United Kingdom and the United States. 
Dual earner support

\begin{tabular}{|c|c|c|c|}
\hline & High & $\begin{array}{c}\text { A } \\
\text { General } \\
\text { family policy } \\
\text { model }\end{array}$ & $\begin{array}{l}\text { B Contradictory } \\
\text { family policy } \\
\text { model }\end{array}$ \\
\hline support & Low & $\begin{array}{l}\text { C } \\
\text { Market-oriented } \\
\text { family policy } \\
\text { model }\end{array}$ & $\begin{array}{l}\text { D } \\
\text { Dual earner } \\
\text { family policy } \\
\text { model }\end{array}$ \\
\hline
\end{tabular}

Figure 1.1 Dimensions and models of family policy. Elaboration from Korpi (2000)

Korpi's typology builds on the characteristics of family policy in the 1990s, and also to a large extent reflects the underlying goals and strengths of different political tendencies. Welfare states having general family policy models are held to be characterized by strong Christian Democratic incumbency throughout the post-war period. Countries with dual earner models of family policy were dominated by left parties during the same time period, while nations with market-oriented models primarily were governed by secular conservative and/or centrist parties.

As is evident from Figure 1.1, a fourth model of family policy could potentially exist, characterized by the criteria of the top right cell (B). This model is not identified in the original typology, and the cell would correspond to a situation of institutional pluralism, where family policies have high scores on support to both the traditional and the dual earner family. Such a combination of family policy is perhaps best described as contradictory, or pluralistic, since the two dimensions reflect different underlying family ideologies. Highly developed support to the traditional family of course entails a strengthened housewife role, which seems to contradict motives of dual earner family support to enable female labour force participation. Empirically, the broad family policy indicators used by Korpi do not take on values corresponding to clear cases of such a contradictory model. However, three countries did have tendencies in this direction (Korpi 2000).

This neither means that such a model could not come into existence,

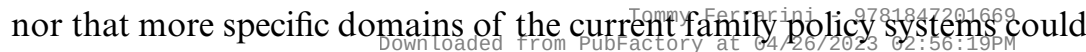


not inhibit similar conflicting, or mixed, features from arising within them (Ferrarini 2003). It is thus an empirical question whether countries have developed in the direction of such a contradictory family policy model. With the view that the welfare state is an arena for distributive struggle between different social and political actors, both along the lines of class and gender, partly conflicting goals of social policies should perhaps be seen as a residue of changing power balances in such ongoing conflicts. In any case, the empty cell indicates that social policies may not always be homogeneous units where all main policy measures work in the same direction.

The institutional approach is used in two different ways in this study. First, the broad family policy typology is utilized to organize information on separate family policy programmes. Thus the typology may for example be used to analyse how particular aspects of family policy transfers deviate from the broader family policy matrix. ${ }^{3}$ Second, the two dimensions underlying the broad typology, general family support and dual earner support, are used as a basis for the construction of agency-relevant indicators of family policy used in empirical analyses.

Korpi's institutional typology has not been accepted without criticism (Hobson 2000; Shalev 2000; Shaver 2000; Quadagno 2000; Ferrarini 2003). Shaver (2000), for example, admits that there are advantages to an institutional approach in that analytical clarity is gained, but also states that too narrow an institutional focus may reduce social policy to an overly limited set of policy institutions. Shaver therefore makes a case for not entirely abandoning holistic typologies that capture the broad outlines of institutional and political regularities, within and between welfare state regimes. Of course Shaver has a point in that broad welfare state typologies sometimes may be useful, but to the extent that they are used to explain a particular outcome it is of course necessary that the typology reflect factors that analytically can be related to the outcome. Shalev (2000) has also rightly pointed out that Korpi exclusively uses political parties to explain the development of the family policy models. Even if classpolitical factors are argued to be important in analyses of welfare state diversity, Shalev (2000) maintains that gender agency ought to be included also as an explanatory factor of family policy institutions. I agree with this argument, even if it should perhaps be underlined that gender-based actors also are likely to operate within and via existing political parties. A working hypothesis in this study is that both gender and class perspectives are needed to explain the expansion of family policy programmes in the advanced welfare democracies. 


\section{ENACTMENT PATTERNS OF SOCIAL POLICY TRANSFERS}

How is the development of family policy related to the enactment of other income maintenance programmes? It has in earlier research been shown that universal child benefits developed relatively late in the advanced industrialized countries as compared to other social transfer programmes, such as pensions and social insurance against unemployment, sickness and work accident (Väisänen 1992; Wennemo 1994). Figure 1.2 shows the most typical periods of introduction of six main forms of social transfers for the 18 countries. To exclude extreme values, only the introduction years for benefits between the second and third quartile of the countries are included, implying that the observation period begins when a quarter of the countries have enacted a particular scheme and ends when three-quarters of the countries have enacted the same scheme.

The timing of the enactment of pensions, unemployment, sickness and work accident insurance is sometimes explained by the degree to which major social and political actors contested such institutions. Work accident insurance and sickness insurance both began to develop relatively early. However, while work accident programmes were introduced during a relatively short time span, with the effect that three out of four countries had introduced such programmes by 1913, sickness insurance did not reach the same level of institutionalization in the welfare democracies until almost three decades later. The longer time span of typical sickness insurance enactment has been attributed to a stronger resistance from employers and conservative political parties against reforms directly intervening in labour market relations, while the shorter introduction period of work accident would be due to the less controversial status of these institutions in this respect (Väisänen 1992). The extent of voluntary arrangements in sickness insurance may to some extent also have delayed the introduction of compulsory insurance (Kuhnle 1978). The even later enactment of unemployment insurance could, according to the same line of thought, be due to the potential of such insurance benefits to even more directly affect labour market relations and create economic and political conflicts of interest (Carroll 1999; Wennemo 1994).

While three out of four countries had enacted all four 'core' social insurance programmes before the Second World War, family policy institutions, in terms of maternity insurance and child benefits, were introduced later. ${ }^{4}$ Several plausible explanations for the later enactment of these family policy benefits exist. Major political actors may have had less interest in such family policy reforms during this period. Social democratic parties, which after the Second World War showed an interest in expanding 


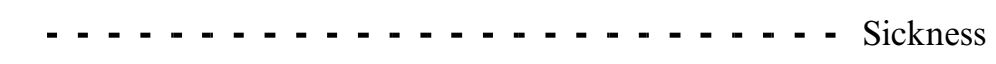

Work accident

Old-age pensions

Unemployment

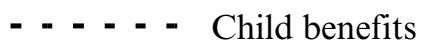

Maternity

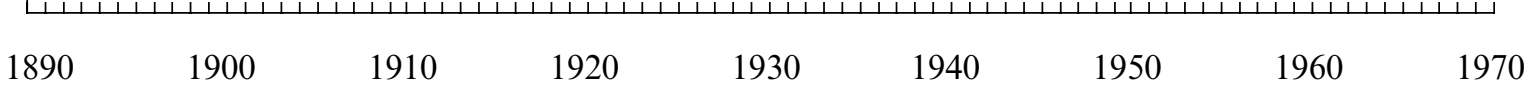

Source: Wennemo (1994) and author's calculations

Figure 1.2 The time period of enactment of the first laws in pensions, unemployment, sickness, work accident, maternity insurance and universal child benefits in 18 countries from the beginning of the second to the end of the third quartile 
child benefits and paid parental leave, in some instances gave higher priority to the development of core social insurance programmes that at the time primarily provided benefits to male workers (Ohlander 1988). Family wage systems had also been implemented in some sectors of early welfare states, providing a subsistence wage to employees with children (Montanari 2000), and possibly decreasing the demand for other types of family benefits.

\section{DATA AND MEASUREMENT ISSUES}

The data used here are based on the Social Citizenship Indicator Programme (SCIP), which is being constructed at the Swedish Institute for Social Research, Stockholm University. The SCIP database comprises institutional information on social rights accruing through old-age pensions, sickness, unemployment, work accident insurance, child benefits as well as marriage subsidies in 18 countries from 1930 to 2000. Existing information in SCIP on child benefits and marriage subsidies are used in this study. To construct measures of different family policy dimensions and analyse how institutions of family policy shape agency and actions of parents, as well as the living conditions of families with young children, I have collected new data on parental leave benefits. Included indicators are estimated net benefit levels, duration and parental eligibility. On the basis of SCIP, net benefit generosity of parental leave benefits has been computed for five main types of parental leave paid to a specified type case family: maternity insurance, dual parental insurance, paternity insurance, maternity grants and childcare leave.

Table 1.1 describes the typical institutional features of the family policy benefits included in the study, as well as their categorization along the two dimensions of family policy discussed above. Maternity insurance programmes are earnings-related and paid to the mother. Dual parental insurance is an earnings-related transfer that can be paid to either parent. Paternity insurance is likewise related to previous earnings, but paid during the immediate post-natal period parallel to maternity insurance. ${ }^{5}$ Childcare leave is a flat-rate benefit paid after the termination of parental insurance leave. Child benefits are not confined to parents with newborn children, but are typically paid monthly from the birth of the child and throughout primary school age. Marriage subsidies are benefits paid via the tax system to households with a main wage earner with an economically non-active spouse, while maternity grants are lump-sum payments made in connection with confinement.

The generosity of different benefits is indicated by the use of strategically chosen type case families, whose earnings are based on average production

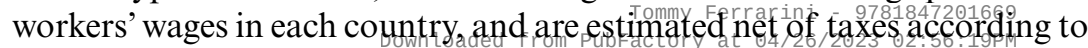


income tax legislations for each benefit. The chosen households are ideal types and should not be seen as reflecting an average family situation in different countries. Instead the different type cases are chosen primarily to reflect the generosity of the different dimensions of family policy and their tendency to support different family types. For example, when calculating marriage subsidies and child benefits the type case is based on a family with a full-time earner and a non-active spouse to reflect the extent to which such a male breadwinner household is sustained, and the generosity of parental leave benefits is evaluated on the basis of a type case family assumed to have two earners, in order to capture the degree of earnings-relatedness in such systems.

Table 1.1 Family policy dimension and typical institutional characteristics of different types of family transfers

Type of benefit

Maternity Insurance

Dual parental insurance

\section{Paternity Insurance}

Childcare

Leave

Child

Benefits

Marriage subsidy

Maternity

Grant support

Family support dimension

Dual earner

Dual earner support

Dual earner support

General family support

General family support

General family support

General family support
Typical institutional features

Earnings-related benefit paid to mother before and after confinement.

Earnings-related benefit paid to mothers and fathers after confinement, sometimes with partial individual entitlement.

Earnings-related benefit paid to be used by father in connection with confinement, simultaneously with maternity insurance.

Flat-rate benefit paid after termination of parental insurance benefit.

Flat-rate benefit frequently paid throughout primary school-age period Tax transfer to wage earner with dependent spouse

Flat-rate and lump-sum payment in connection with confinement. 
The combination of existing and new data make possible an institutional analysis of the forms of family policy benefits, together or separately, as well as the construction of indicators of different institutional dimensions of family policy. By being able to measure dual earner support and general family support on continuous scales and allow each country's family policy to vary along both dimensions simultaneously, the possibilities to identify relationships between potential causal factors, institutions and outcomes in statistical analyses are improved. Thereby this approach also allows for family policies to reflect more or less contradictory, or pluralistic, orientations regarding support to given types of family structures.

As discussed above, the development of data over state-legislated social rights in several respects is an advance compared to the use of expenditure levels in important respects. Kangas's (1991) comparison of spending levels and social rights in sickness insurance suggests that different dynamics are at work in the development of expenditure and social rights, and that the variation in political power constellations mainly influence rights development. The level of social rights is not the only determinant of social spending on a particular benefit, but many structural factors such as unemployment levels and the demographic composition of the labour force by age and sex also have an impact on sickness insurance expenditures. Similar problems with expenditure data exist in other parts of social insurance systems (see Palme 1990; Carroll 1999). Regarding, for example, paid parental leave, it can be assumed that factors such as the extent of female employment, unemployment levels and the age structure of the female population probably are likely to have different impacts on spending levels than on the legislation governing such transfers.

The character of the social rights data at disposal here makes it suitable for descriptive analysis over time as well as for quantitative multivariate analysis such as pooled time-series cross-section regressions. The latter sets of methods combine cross-sectional data with time-series data and thereby enhances the potential to simultaneously control for several independent variables in evaluations of causes and outcomes of paid leave development. One drawback with the method is that only one coefficient summarizes the effect of an independent variable in the pooling of observations both over time and space, and that it thereby is assumed that the causal effect is the same across all units of analysis (Shalev 1998). A further potential problem is that data here exists only for every fifth year, which means that changes in legislation occurring between the five years are not precisely accounted for, introducing constraints on available statistical techniques.

On the whole, however, using separate indicators on the development of determinate types of family policy transfers can be expected to improve the

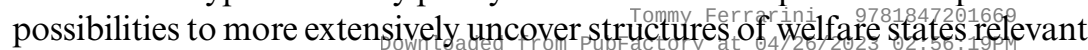


for living conditions and behaviour of individuals in comparative analyses. Consider the following example. Suppose that a researcher wants to analyse the relationship between family policy and female labour force participation in two types of countries, A and B. In type A countries, family policy transfers have been instituted with the goal to support female paid work, while benefits in countries of type B are paid in support of traditional family patterns. Let us also assume that the different types of transfers actually achieve their original goals, so that country A has high levels and country B has low levels of female labour force participation. Conflating the two types of benefits into a single leave category could lead us to falsely conclude that family policy transfers do not affect female economic activity. A separation of the two types of benefits can help us to uncover this difference.

Several important aspects of family policy transfer systems have been left out of the analysis in this study due to a shortage of reliable longitudinal data. Institutional data have primarily been collected so as to analyse broad strategies of family policy transfers, which means that information on several significant institutional aspects and outcomes of such benefits are lacking. Data on coverage and take-up of family policy benefits in the relevant populations has, for example, not been collected. ${ }^{6}$ Furthermore, the study does not include separate information needed for focusing on family policy legislation and outcomes for particular groups in the population, such as single mothers, ethnic minorities and gay/lesbian couples. Defining such limits of scope does of course not mean that the broader institutional structures of family policy may not have bearings for such population groups, but this is a challenge for future research to accept.

Other types of data are also used in the study. In analyses of family policy transfers and poverty outcomes, for example, income distribution data from the Luxembourg Income Study (LIS) are used. The LIS project provides micro-level income data where income and demographic concepts have been harmonized so as to increase cross-national comparability (Smeeding 2001). The analyses of attitudes use the International Social Survey Programme's (ISSP) comparative attitudinal data from the module 'Family and changing gender roles' collected in 2002 (ISSP 2005). In analyses of the demographic macro-outcomes of family policy transfers, total fertility level data has been collected from the United Nations Demographic Yearbook (various years), while data on age-specific levels of female labour force participation is drawn from International Labour Organization's (ILO) Yearbook of Labour Statistics (various years). These data have been specifically collected to fit the research questions in this study. The LIS database enables analysis of poverty of families with the youngest children that are most likely to be directly affected by the type of family policy legislation studied here.

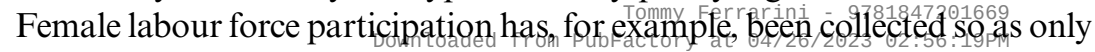


women in the prime childbearing ages are included, thus enabling a closer fit between the institutional variables (particular types of family support) and the potential outcome (female economic activity). The following section outlines the main structure of the book.

\section{OUTLINE OF THE BOOK}

The following chapters together aim to elucidate the same underlying question: to what extent and in which way do family policy shape agency and well-being of individuals? Chapter 2 consists of an analysis of the institutional development of family policy benefits in the 18 countries from 1950 to 2000 , dealing with how such social policy institutions structure incentives and agency of parents with regard to paid and unpaid work. The separate components of benefits are analysed, before I construct two separate dimensions of family policy, reflecting programme extension in favour of general family support or dual earner support. In this chapter these dimensions, that are primarily based on family policy transfers, are also evaluated against aspects of the broader family policy setting - including also public services, for which reliable data mainly exist for the end of the studied period. Chapter 3 evaluates the relationship between economic as well as political determinants on one hand, and the institutional development of family policy dimensions on the other, between 1970 and 2000. Chapter 4 is devoted to simultaneous analyses of the relationship of the different types of family policy on fertility levels and female employment between 1970 and 2000. Chapter 5 examines relationships between the generosity of family policy and poverty among families with young children between 1980 and 2000. Chapter 6 analyses links between models of family policy and attitudes to women's work, as well as perceived problems reconciling work and family life. Each of these chapters thus seeks to bring clarity to specific questions, which separately and taken together aim to generate new answers on central macro-social processes and conditions in advanced welfare states. The seventh and final chapter contains a summary discussion on macrolevel links between family policy strategies and different socioeconomic, demographic and attitudinal outcomes, as well as a brief outline of future agendas and challenges for researchers and policymakers.

\section{NOTES}

1. Korpi's typology was originally presented in an article in Social Politics where it is combined with Korpi and Palme's (1998) class-based typology to explain patterns of class and gender inequality. 
2. The general family support dimension is in the original typology based on indicators reflecting tax benefits to dependent spouses and children, cash child benefits and the extent of childcare facilities for older pre-school children. The dual earner dimension of family support is based on the quality of public childcare available to the youngest children ( $0-2$ years), the extent of social services provided to elderly persons and the generosity of earnings-related parental insurance benefits for mothers as well as the presence of a period of paid leave for fathers (Korpi 2000: 145-6).

3. Even if indicators of family policy benefits are included in the basis of the typology, these are approximate and do not cover more fine-tuned facets of family policy, such as net rates of replacement in parental leave or the presence of childcare leave benefits. It is therefore also of interest to analyse how institutionally refined measures of family policy relate to the broader models of family policy.

4. It would here of course be interesting to analyse the introduction of different family policy transfers and services at a broader scale, such as public childcare and various tax transfers for dependent children and spouse, but information on introduction years does not exist for such programmes. Benefits that entitle fathers to paid parental leave were, furthermore, not introduced until the mid-1970s, and only ten of the 18 countries had introduced some type of parental leave transfer directed to fathers by 2000 .

5. The use of the term 'parental insurance' in this study does not imply that actuarial or quasi-actuarial principles underlie these benefits, but rather connects to a wider concept of social insurance, with the term connoting contingency-based benefits usually based on a contributions test. For a discussion see, for example, Barr (1993).

6. However, when for example analysing potential impacts of paid parental leave on female labour force participation, the use of coverage of earnings-related components as an explanatory variable would be tautological, as it largely is an outcome of female labour force participation itself. 